\section{CLIFF SHAW AWARD}

The Cliff Shaw Award is given anally to an individual who has made significant contribution to natural story through an article in the Blue y. At the 1973 Annual Meeting of e Society, a joint award was made to Is. Laura Hoyte and Ms. Thelma epper. Ms. Hoyte wrote about her exriences feeding birds, including a olden Eagle, at Pike Lake, Saskat- chewan, in "Feeding the hungry" in the March, 1973 Blue Jay. Ms. Pepper described the plantings, the food she uses, and some of the visitors at the feeding station on her city lot in Saskatoon in "Bird watching - indoors" in the same issue. Both authors wrote articles that demonstrate how anyone, whether they live in city or country, can enhance their enjoyment of nature by attracting birds to within a few feet of kitchen or living room wind ows.

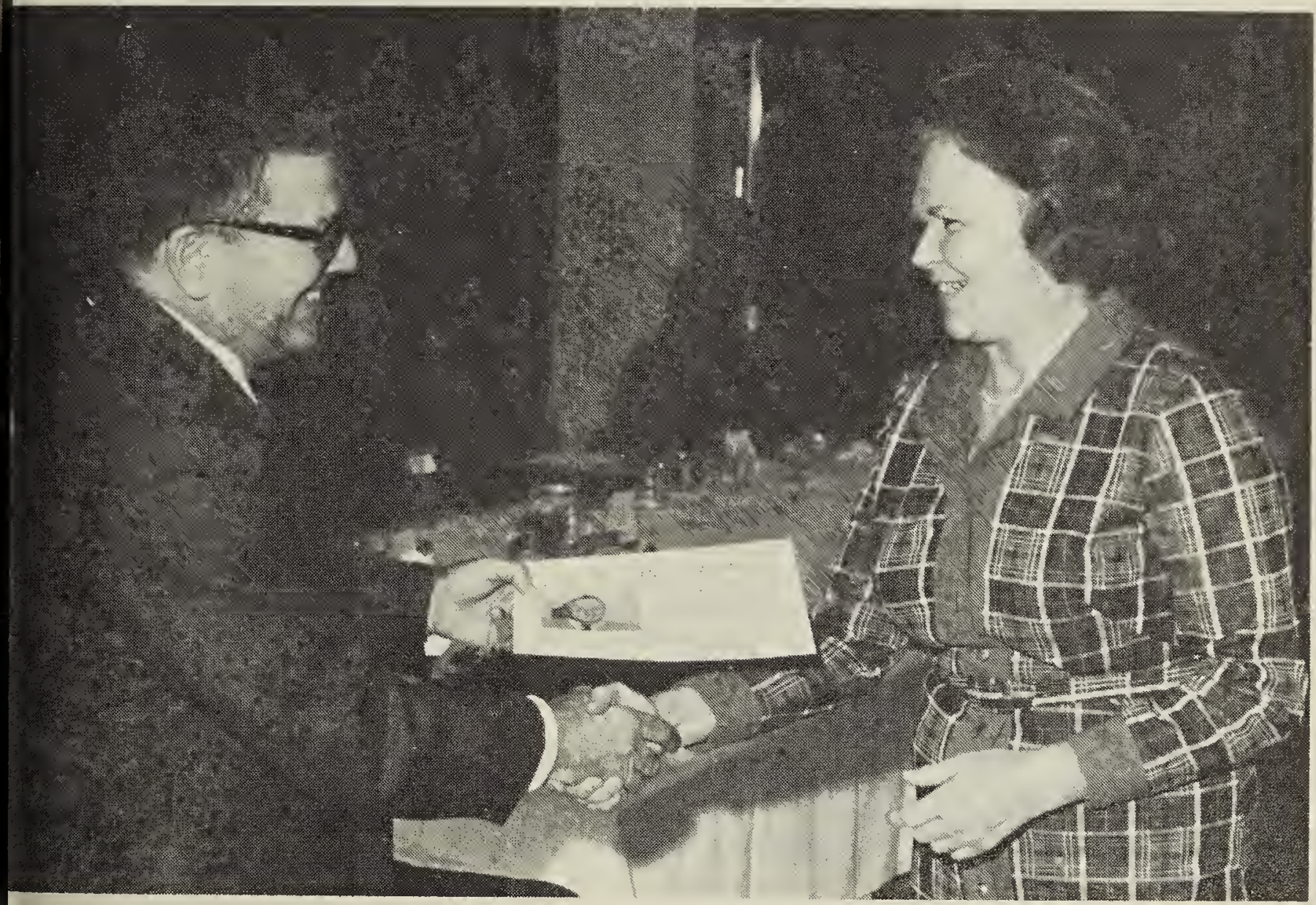

G. W. Seib We jay editor, Bernard Gollop, presents the SNHS Cliff Shaw Award to co-winner, helma Pepper. Laura Hoyte could not be present to receive her share of the award.

\title{
SASKATCHEWAN NATURAL HISTORY SOCIETY Financial Statement - Year Ending September 30, 1973
}

\section{NCOME}

Memberships (including sales of Blue Jay)

Memberships (extra re: supporting and sustaining

Spec. Pub. No. I Guide to Sask. Mammals ...

Spec. Pub. No. 2 Birds of Sask. River .......

Spec. Pub. No. 3 Birds of Regina ...........

Spec. Pub. No. 4 Blue Jay Index ..............

Spec. Pub. No. 5 Birds of Lake Athabasca ....

Spec. Pub. No. 6 Birds of NE Sask. . . . . . . .

Spec. Pub. No. 7 Birds of Moose Mountain ..

Publication - Hours and the Birds .........

Publication - Birds of the Elbow $\ldots \ldots \ldots$
$\$ 7,161.64$

$2,130.75$

$\$ 9,292.39$ 